\title{
PENGARUH PIJAT BAYI TERHADAP LAMA TIDUR BAYI DI DESA DUWET KECAMATAN WONOSARI KABUPATEN KLATEN
}

\author{
Warsini $^{1}$, Dyah Nugraini ${ }^{2}$
}

\begin{abstract}
Background: Even the oldest massage is an activity used by humans to expel fatigue and stress. Lack of information and knowledge of parents of massage, makes many parents think a massage is not a scientific and natural form of therapy for infants. Most mothers believe massage is necessary only when their child had flu and colds.

Purpose of the study: To determine the effect of infant massage on infant sleep duration in the village of Duwet, Wonosari Subdistrict, Klaten Regency.

The subject: The population in this study is a baby in the village of Duwet Wonosari District of Klaten regency totaling 45 babies. Samples that met the study criteria and amounted to 20 babies. The sampling technique is simple random sampling.

Methods: The data collection is done by the experimental method is by measuring how much sleep babies after intervention. Data were analyzed using statistical tests Independent t-test.

The results: Long sleep in infants that give the infant massage is known that at least 11 hours and a maximum of 18 hours with an average bed is 15.90 hours. Long sleep in infants who were not given the infant massage is known at least 12 hours and a maximum of 17 hours with an average bed is 13.90 hours. Statistical analysis showed p: 3.967 with an upper limit 0.047 and lower limit 0.33. Conclusion: There is a statistically significant effect of infant massage with infant sleep duration (p: 3.967 with an upper limit 0.047 and lower limit 0.33).
\end{abstract}

Keywords: infant massage, infant sleep duration

\section{PENDAHULUAN}

Pijat sebagai sebuah keahlian sudah memiliki sejarah yang sangat panjang. Bahkan pijat merupakan kegiatan tertua yang digunakan manusia untuk mengusir kelelahan dan stres. Pada awal kemunculannya, pijat dipercaya sebagai salah satu cara paling baik untuk meredakan rasa lelah, stres, otot kaku dan pegal-pegal. (Syaukani, 2015) Pijat bayi tentu saja hadir beriringan dengan lahirnya kemampuan manusia dalam melakukan terapi pijat. Karena, pijat bayi juga diartikan sebagai sentuhan komunikasi yang nyaman antara ibu dan bayi. Pijat bayi merupakan pengungkapan rasa kasih sayang antara orang tua dengan anak lewat sentuhan pada kulit. Sentuhan dan pelukan seorang ibu merupakan kebutuhan dasar bayi. Dimana semua itu memiliki dampak yang luar biasa bagi perkembangan bayi. Sentuhan yang dihadirkan dalam pijatan-pijatan lembut untuk bayi merupakan sebuah stimulasi yang penting dalam tumbuh kembang anak. Anak yang mendapat stimulus terarah dan teratur akan lebih cepat berkembang dibandingkan dengan anak yang kurang atau tidak mendapat stimulus. (Syaukani, 2015) 
Naluri seorang bayi merespon sentuhan ibu sebagai sebuah bentuk perlindungan, perhatian, dan ungkapan cinta. Kita bisa melihat bayi yang mendapatkan sentuhan terlihat begitu nyaman dan tenang. Semakin tinggi frekuensi sentuhan, semakin dekat hubungan batin yang terjalin antara bayi dan orang terdekatnya. Sentuhan yang dihadirkan pada bayi dalam bentuk pijatan lembut sebaiknya dilakukan oleh orang-orang terdekat bayi seperti lbu, Ayah, Kakek atau Nenek. Kurangnya informasi dan pengetahuan orang tua terhadap pijat, menjadikan banyak orang tua menganggap pijat bukanlah sebuah bentuk terapi ilmiah sekaligus alamiah bagi bayi. Sebagian besar ibu-ibu berpendapat pijat hanya perlu dilakukan ketika anaknya mengalami sakit flu dan masuk angin. (Handayani, et al., 2012)

Salah satu respon yang bisa dilihat jika dilakukan pemijatan secara teratur adalah respon tidur. Tidur adalah bagian dari penyembuhan, perbaikan dan proses fisiologis yang berputar dan bergantian dengan periode jaga yang lebih lama. Mencapai kualitas tidur yang baik penting untuk kesehatan, sama halnya dengan sembuh dari penyakit. Setengah dari seluruh waktu tidur bayi digunakan untuk tidur aktif atau tidur tahap Rapid Eye Movement (REM). Para ahli pediatrik mengatakan, tidur aktif ini penting bagi bayi untuk membangun sirkuit otak. Saat tidur, otak bayi justru lebih aktif daripada saat terjaga. Bayi butuh banyak tidur untuk mengembangkan otot, tangan, dan kaki serta struktur kerangka tubuhnya. Penting bagi bayi untuk tidur nyenyak di tempat tidur yang nyaman. (Potter dan Perry, 2010)

Mengingat akan pentingnya waktu tidur bagi perkembangan bayi maka kebutuhan tidurnya harus benar- benar terpenuhi. Agar tidak berpengaruh buruk terhadap perkembangannya, setiap bayi mempunyai pola tidur masingmasing yang tidak sama pada setiap bayi. Salah satu cara yang dapat digunakan untuk meningkatkan tidur bayi adalah dengan pemijatan. Bayi yang dipijat akan dapat tidur dengan lelap, sedangkan pada waktu bangun daya konsentrasinya akan penuh. (Handayani, et al., 2012)

Studi pendahuluan yang dilakukan di Desa Duwet Kecamatan Wonosari Kabupaten Klaten, diketahui ibu yang mempunyai bayi sejumlah 45 ibu dan beberapa ibu yang mempunyai bayi mengatakan belum mengerti cara melakukan pijat bayi yang tepat dan ibu bayi mengatakan bayinya sering rewel dan susah tidur. Di Desa Duwet Kecamatan Wonosari Kabupaten Klaten juga belum pernah dilakukan penelitian tentang manfaat pijat bayi.

\section{TUJUAN PENELITIAN}

\section{Tujuan Umum}

Untuk mengetahui pengaruh pijat bayi terhadap lama tidur bayi di Desa Duwet Kecamatan Wonosari Kabupaten Klaten.

2. Tujuan Khusus

a. Untuk mengetahui lama waktu tidur bayi yang diberi terapi pijat bayi di Desa Duwet Kecamatan Wonosari Kabupaten Klaten.

b. Untuk mengetahui lama waktu tidur bayi yang tidak diberi terapi pijat bayi di Desa Duwet Kecamatan Wonosari Kabupaten Klaten.

\section{DESAIN PENELITIAN}

Penelitian ini merupakan penelitian eksperimental dengan rancangan post-test desain. 


\section{POPULASI, SAMPEL DAN} TEKHNIK SAMPLING

1. Populasi

Populasi dalam penelitian ini adalah adalah bayi di Desa

Duwet Kecamatan Wonosari

Kabupaten Klaten yang berjumlah 45 bayi.

2. Sampel

Sampel penelitian adalah bayi di Desa Duwet Kecamatan Wonosari Kabupaten Klaten yang memenuhi kriteria penelitian sejumlah 20 bayi. Adapun kriteria tersebut meliputi :

a. Kriteria inklusi

Kriteria inklusi merupakan kriteria dimana subyek penelitian memenuhi syarat sebagai sampel, yang meliputi: bayi sehat, berusia 0-12 bulan dan tidak sedang dalam masa pengobatan.

b. Kriteria eksklusi

Kriteria eksklusi merupakan kriteria dimana subyek penelitian tidak dapat mewakili sampel karena memenuhi syarat sebagai sampel, yang meliputi: bayi sedang sakit, bayi sedang dalam masa pengobatan, dan orang tua bayi tidak bersedia menjadi responden.

Sampel kemudian dibagi menjadi 2 kelompok yaitu 10 bayi sebagai kelompok yang diberi perlakuan dan 10 bayi sebagai kelompok kontrol.

3. Tekhnik sampling yang digunakan adalah simple random sampling. Pengumpulan data dilakukan dengan metode eksperimental yaitu dengan cara mengukur lama tidur bayi setelah dilakukan intervensi. Intervensi yang diberikan yaitu pijat bayi sehari sekali selama 1 minggu. Data kemudian dianalisa dengan menggunakan uji statistik Independent $t$-test.
HASIL PENELITIAN

1. Gambaran umum Lokasi

Penelitian

Dalam penelitian ini peneliti memilih lokasi penelitian di Desa Duwet Kecamatan Wonosari Kabupaten Klaten. Balita yang ada di Desa Wonosari yaitu sejumlah 45 bayi. Penelitian ini dilakukan pada bulan September 2015 sampai bulan Februari 2016. Pengambilan data dilakukan pada bulan Desember 2015 sampai Januari 2016.

2. Karakteristik Responden

a. Berdasarkan umur bayi Tabel 1

\begin{tabular}{ccc}
\hline $\begin{array}{c}\text { Usia } \\
\text { (bulan) }\end{array}$ & $\mathrm{f}$ & $\%$ \\
\hline 2 & 3 & 15,0 \\
\hline 3 & 3 & 15,0 \\
\hline 4 & 2 & 10,0 \\
\hline 5 & 1 & 5,0 \\
\hline 6 & 5 & 25,0 \\
\hline 7 & 1 & 5,0 \\
\hline 8 & 2 & 10,0 \\
\hline 9 & 2 & 10,0 \\
\hline 12 & 1 & 5,0 \\
\hline Jumlah & 20 & 100,0 \\
\hline Sumber : Data Primer, 2016
\end{tabular}

Dari tabel 1 diketahui bahwa sebagian besar responden berumur 6 bulan yaitu sebanyak 5 responden (25\%) dan paling sedikit adalah usia 5 bulan, 7 bulan dan 12 bulan yaitu masing-masing sebanyak 1 bayi (5\%). 
b. Berdasarkan Umur lbu

Tabel 2

\begin{tabular}{ccc}
\hline Usia (tahun) & $f$ & $\%$ \\
\hline 21 & 1 & 5,0 \\
\hline 22 & 2 & 10,0 \\
\hline 23 & 1 & 5,0 \\
\hline 24 & 2 & 10,0 \\
\hline 25 & 3 & 15,0 \\
\hline 26 & 1 & 5,0 \\
\hline 27 & 2 & 10,0 \\
\hline 28 & 1 & 5,0 \\
\hline 30 & 1 & 5,0 \\
\hline 32 & 2 & 10,0 \\
\hline 35 & 2 & 10,0 \\
\hline 36 & 1 & 5,0 \\
\hline 39 & 1 & 5,0 \\
\hline Jumlah & 20 & 100,0 \\
\hline Sumber : Data Primer, 2016
\end{tabular}

Sumber : Data Primer, 2016

Tabel 2 menunjukkan bahwa umur ibu bervariasi berkisar antara 21 tahun sampai dengan 39 tahun dengan ratarata 27,90 tahun. Umur ibu paling banyak yaitu 25 tahun, sebanyak 3 orang (15\%).

c. Berdasarkan Pekerjaan lbu

Tabel 3

\begin{tabular}{ccc}
\hline Pekerjaan Ibu & $\mathrm{f}$ & $\%$ \\
\hline buruh & 4 & 20,0 \\
\hline guru & 1 & 5,0 \\
\hline $\begin{array}{c}\text { ibu rumah } \\
\text { tangga }\end{array}$ & 10 & 50,0 \\
\hline swasta & 2 & 10,0 \\
\hline wiraswasta & 3 & 15,0 \\
\hline Jumlah & 20 & 100,0 \\
\hline
\end{tabular}

Sumber : Data Primer 2016

Dari tabel 3 diketahui bahwa sebagian besar ibu bayi tidak bekerja yang ditunjukkan dengan status menjadi lbu Rumah Tangga yaitu sebesar $50 \%$.
3. Hasil Penelitian
a. Lama Tidur Bayi yang Dipijat

Tabel 4

\begin{tabular}{cccccc}
\hline \multicolumn{6}{c}{ Lama Tidur Bayi } \\
\hline & $\mathrm{n}$ & $\min$ & mak & mean & $\begin{array}{c}\text { St. De } \\
\text { viasi }\end{array}$ \\
\hline $\begin{array}{ccccc}\text { Lama } \\
\text { tidur }\end{array}$ & 0 & 11 & 18 & $\begin{array}{c}15,9 \\
0\end{array}$ & 2,378 \\
\hline \multicolumn{5}{c}{ Sumber : Data Primer, 2016}
\end{tabular}

Dari tabel 4 diketahui bahwa lama tidur paling sedikit pada bayi setelah diberi pijat bayi adalah 11 jam dan paling lama 18 jam dengan rata-rata tidur adalah 15,90 jam per hari.

b. Lama Tidur Bayi yang Tidak Dipijat

Tabel 5

\begin{tabular}{|c|c|c|c|c|c|}
\hline \multicolumn{6}{|c|}{ Lama Tidur Bayi } \\
\hline & $\mathrm{n}$ & $\min$ & mak & mean & $\begin{array}{c}\text { St. De } \\
\text { viasi }\end{array}$ \\
\hline $\begin{array}{l}\text { Lama } \\
\text { tidur }\end{array}$ & $\begin{array}{l}1 \\
0\end{array}$ & 12 & 17 & $\begin{array}{c}13,9 \\
0\end{array}$ & 1,729 \\
\hline
\end{tabular}

Dari tabel 5 diketahui bahwa lama tidur paling sedikit pada bayi yang tidak diberi pijat bayi adalah 12 jam dan paling lama 17 jam dengan rata-rata tidur adalah 13,90 jam per hari.

c. Pengaruh Pemberian Pijat Bayi terhadap Lama Tidur Bayi

Tabel 6

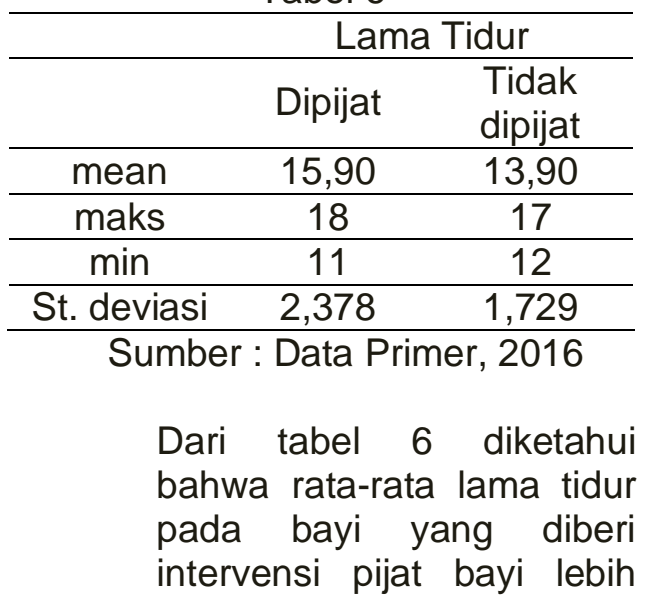


lama yaitu 15,90 jam, daripada bayi yang tidak diberi intervensi pijat bayi yaitu 13,90 jam.

Dari pengolahan data menggunakan SPSS versi 18 nilai t-test : 0,047 dengan batas atas 3,967 dan batas bawah 0,33. Dengan demikian dapat disimpulkan bahwa terdapat pengaruh yang secara statistik signifikan antara pijat bayi dengan lama tidur bayi.

\section{PEMBAHASAN}

Pijat merupakan kegiatan tertua yang digunakan manusia untuk mengusir kelelahan dan stres. Pada penelitian ini tindakan pijat bayi diberikan untuk mengetahui pengaruhnya terhadap lama tidur bayi.

Dari karakteristik responden yang didapatkan dari hasil penelitian yang telah dilakukan diketahui bahwa umur bayi yang dijadikan sebagai responden bervariasi. Demikian juga umur ibu bayi juga bervariasi dengan rentang umur 21-39 tahun dengan umur terbanyak adalah 25 tahun yaitu $15 \%$. Hal ini dapat dipahami bahwa usia 25 tahun merupakan usia reproduksi sehat sehingga para ibu memanfaatkan rentang usia tersebut untuk mempunyai anak.

Berdasarkan karakteristik pekerjaan ibu bayi diketahui bahwa sebagian besar ibu bayi tidak bekerja yang ditandai dengan status menjadi lbu Rumah Tangga. Waktu yang dibutuhkan untuk merawat bayi dan mengurus keperluan rumah tangga akan menuntut waktu yang lebih banyak bagi para ibu bayi untuk tetap berada di dalam rumah. Hal ini membuat para ibu bayi tidak bekerja.

Menurut hasil penelitian yang dilakukan diketahui bahwa rata-rata lama tidur bayi yang diberi pemijatan adalah 11 jam dan paling lama 18 jam dengan rata-rata tidur adalah 15,90 jam per hari. Rata-rata lama tidur ini lebih tinggi dari teori yang ada karena menurut Potter dan Perry (2010), pola tidur normal pada bayi yaitu biasanya beberapa kali tidur siang, namun tidur rata-rata selama 8 sampai 10 jam di malam hari dengan waktu tidur total 15 jam setiap hari.

Sedangkan hasil penelitian pada bayi yang tidak dipijat diketahui bahwa lama tidur paling sedikit adalah 12 jam dan paling lama 17 jam dengan rata-rata tidur adalah 13,90 jam per hari. Rata-rata lama tidur ini lebih rendah dari teori yang ada yaitu rata-rata selama 8 sampai 10 jam di malam hari dengan waktu tidur total 15 jam setiap hari. (Potter dan Perry, 2010)

Dari hasil analisis statistik diketahui bahwa terdapat pengaruh yang secara statistik signifikan antara pijat bayi dengan lama tidur bayi ( $p$ : 0,047 dengan batas atas 3,967 dan batas bawah 0,33 ).

Lama tidur yang lebih banyak ini dikarenakan bahwa pada saat bayi dipijat maka tubuh bayi akan melepaskan oksitosin dan endorfin. Endorfin merupakan hormon pereda nyeri sehingga mengusir rasa tidak nyaman dan meningkatkan kualitas tidur. (Handayani, et al., 2012)

Hasil penelitian ini juga sesuai dengan hasil penelitian Minarti dan Utami (2012), yang menyatakan bahwa ada dampak dari pijat bayi untuk kualitas tidur pada bayi usia 36 bulan di kabupaten kerja Puskesmas II Denpasar Timur (Asymp. P titik value 0,000 ( $\rho \leq$ $0,05)$ ).

Pada penelitian ini kualitas tidur yang meningkat ditunjukkan dengan meningkatnya kuantitas tidur pada bayi menjadi lebih tinggi. Selain 
pelepasan oksitosin dan endorfin juga diketahui bahwa pada pemijatan terutama daerah perut juga dapat menstimulasi dan membantu sistem pencernaan. Pemijatan ini dapat merangsang saraf vagus yang salah satu fungsinya meningkatkan daya peristaltik kontraksi berirama yang menggerakkan makanan melewati saluran pencernaan. Dengan pencernakan yang baik maka bayi akan merasakan nyaman dan tidur lebih pulas. (Syaukani, 2015)

Aktivitas pemijatan juga akan meningkatkan aktivitas neurotransmitter serotonin, yaitu meningkatkan kapasitas sel reseptor yang berfungsi mengikat glucocorticoid (adrenalin, suatu hormon stres). Proses ini akan menyebabkan terjadinya penurunan kadar hormon adrenalin, penurunan kadar hormon ini akan meningkatkan daya tahan tubuh terutama Immunoglobulin $M$ (IgM) dan Immunoglobulin $G$ (lgG). Sehingga pada bayi yang mendapatkan pemijatan akan mempunyai daya tahan tubuh yang lebih baik. (Syaukani, 2015) Hal ini menjadikan bayi lebih sehat dan tidak mudah sakit. Pada bayi yang sehat akan mempunyai pola tidur yang normal.

Menurut Irmawati (2015), pada saat proses pemijatan pada bayi akan membuat bayi merasa lebih tenang. Pijatan yang lembut pada kulit bayi akan menenangkan bayi. Hal ini juga diperkuat oleh Handayani, et al., 2012), bahwa pijat bayi akan membangun bounding lewat kontak mata, kulit, aroma tubuh dan suara sehingga akan memberikan manfaat yang optimal bagi khususnya bagi kuantitas dan kualitas tidur pada bayi.

Hasil penelitian ini juga sesuai dengan hasil penelitian Aden, Badi'ah dan Lestiawati (2012), yang menyatakan bahwa terdapat pengaruh pijat bayi terhadap kualitas tidur bayi berusia 6 sampai 12 bulan di Klinik Terapi Bu Ning, Janti, Caturtunggal, Depok, Sleman.

\section{KESIMPULAN DAN SARAN}

1. Kesimpulan

a. Dari hasil penelitian diketahui bahwa pada kelompok bayi yang diberi tindakan pijat bayi maka lama tidur paling sedikit adalah 11 jam dan paling lama 18 jam dengan rata-rata tidur adalah 15,90 jam per hari. Sedangkan pada bayi yang tidak diberi pijat bayi maka lama tidur paling sedikit 12 jam dan paling lama 17 jam dengan rata-rata tidur adalah 13,90 jam per hari.

b. Dari hasil analisis statistik Independent $t$-test diperoleh nilai $p: 0,047$ dengan batas atas 3,967 dan batas bawah 0,33 . Dengan demikian dapat disimpulkan bahwa terdapat pengaruh yang secara statistik signifikan pada pijat bayi terhadap lama tidur bayi.

\section{Saran}

a. Bagi Responden

Setelah mengetahui manfaat pijat bayi maka diharapkan dapat menerapkan dalam kehidupan sehari-hari sebagai cara untuk meningkatkan lama tidur bayi.

b. Bagi Peneliti Selanjutnya

Bagi peneliti selanjutnya dapat melanjutkan penelitian yang lebih mendalam dengan jumlah responden yang lebih banyak dan variabel penelitian yang lebih luas.

\section{Keterbatasan}

Keterbatasan dalam penelitian ini adalah:
a. Peneliti hanya mengambil responden sebanyak 20 
responden penelitian hanya terbatas.

b. Pengambilan data hanya menggunakan lembar observasi dan peneliti tidak dapat mengamati dan memantau lama tidur bayi setiap hari.

\section{DAFTAR PUSTAKA}

Abata, Qorry 'Aina. 2015. Merawat Bayi Baru Lahir. Yayasan PP Al-Furqon, Madiun.

Handayani, Dewi, et al. 2012. Perawatan Bayi Baru : Paduan Lengkap untuk Ibu Merawat Bayi 0-6 Bulan. PT Aspirasai Muda, Jakarta.

Irmawati. 2015. Bayi dan Balita Sehat dan Cerdas. PT Elex Media Komputindo, Jakarta.

Potter, Patricia A. dan Anne G. Perry. 2010. Fundamentals of Nursing, Edisi VII Buku 3. Alih bahasa Diah Nur Fitriani, Onny Tampubolon, dan Farah Diba. Salemba Medika, Jakarta.
Syaukani, Aulia. 2015. Petunjuk Praktis Pijat Senam dan Yoga Sehat untuk Bayi. Araska, Yogyakarta.

Aden, Herdianto M., Badi'ah, Atik, dan Lestiawati, Endang. 2012. "Pengaruh Pijat Bayi terhadap Kualitas Tidur pada Bayi Umur 6-12 Bulan di Klinik Terapi Bu Ning Janti, Depok, Sleman, Yogyakarta".

URL:http://journal.respati.ac.id/ index.php/medika/article/ viewFile/32/28. Diakses 13 November 2015.

Minarti, Ni Made Aries, dan Utami, Kadek Cahya. 2013. "Pengaruh Pijat Bayi terhadap Kualitas Tidur Bayi Usia 3-6 Bulan di Wilayah Kerja Pukesmas II Denpasar Timur". URL:http://download.portalgar uda.org/article. Diakses 13 November 2015.

1 Dosen AKPER Panti Kosala Surakarta

2 Mahasiswa AKPER Panti Kosala Surakarta 